\title{
Distant Partners: A Case Study of Global Virtual Teams Between Spain and South Korea
}

\author{
Enrique Planells-Artigot and Santiago Moll-Lopez
}

\section{Introduction and Theoretical Framework}

This study stems from a strong belief in preparing university students for the demands of a rapidly evolving business world. Higher education institutions, and business schools in particular, occupy a crucial role where they must adapt to the demands of society constantly. The creation of diverse real-life collaborative activities in higher education is a way to learn the required skills in a professional context. They represent a superb method of bridging the gap between academia and the professional world by implementing activities aimed at improving efficiency and constantly revising best practices in class (Kupriyanova et al. 2018: 616-617). Cross-institutional projects and peer learning offer many opportunities for students and teachers alike to constantly reflect on how to make the most of the programmes and develop ongoing efficient programmes and learning opportunities. International collaborative projects in higher education stand out as unique opportunities to develop learning experiences without encountering additional expenses or material resources, which can prove to be an additional burden both for participants and organisers (Sutanto et al. 2011; Taras et al. 2013; Ubachs and Henderikx 2018). Incurring an extra economic burden could deter many professionals and students from a collaborative experience. Thus, technology provides a wide range of tools that create a realistic rendering of what international projects can be, despite the semi-controlled scenarios where instructors act as facilitators and coordinators of activities. Sutanto et al. (2011) demonstrated the importance of establishing adequate coordination mechanisms for Global Virtual Teams (GVT). Likewise, there must be a constant reflection of the available resources

\footnotetext{
E. Planells-Artigot $(\varangle)$

ESIC Business \& Marketing School, Valencia, Spain

e-mail: enrique.planells@esic.edu

S. Moll-Lopez

Universitat Politècnica de València, Valencia, Spain

e-mail: sanmollp@mat.upv.es 
together with the expected learning outcomes, leading to an ongoing improvement of educational tools. By prioritising peer learning, collaborative projects and cultural awareness, business students can reflect on some of the skills they will subsequently have to adopt in their careers. At the same time, they will develop and acquire additional abilities which could not be integrated in class without the support of technology.

In order to achieve this goal, new learning methodologies and technology-based activities are being applied with a basic purpose: to transform a passive learning, in which students act as passive receivers of information, into a learning based on active and constructive strategies in which the responsibility for learning is transferred to the student while receiving frequent feedback from the instructors. Active learning can be defined as any instructional method or pedagogy that involves students in the learning process. Digital media technologies, specifically, offer various tools for collaborative learning and student-centred learning (Bozdağ 2018: 680). European Higher Educations institutions can also offer several options allowing physical or virtual mobility among students, from the use of MOOCs to joint PhDs. These activities allow the students to have an alternative to international mobility programmes, in case they cannot afford them, with the advantage of being tailor-made to their curricula needs (Ubachs and Henderikx 2018).

This paper covers a cross-cultural assignment between two higher education institutions aiming at illustrating the importance of time management, improving communication skills and the awareness of cultural differences in business. Training business intelligence and cultural awareness among students can bring up positive results for future careers (Rehg et al. 2012), as it guarantees adequate preparation in abilities that will be crucial in the business world. Equally, cross-cultural awareness is a necessary skill in the business context, and its correct implementation can result in successful business ventures. Thus, business schools undertake numerous efforts to integrate cultural awareness in their study plans, conscious of developing new 'educational tools' so that students are better prepared for the professional world (Jurše and Matjaž 2011; Rehg et al. 2012). Business schools are pivotal in order to establish networks which expand the world vision of their students and, at the same time, improve the efficiency of managing projects and businesses (Jurše and Matjaž 2011).

This project understands interculturality as something "dynamic and continuously changing" (Bozdağ 2018: 680). By working with two different multicultural groups of university students located in Spain and South Korea, the project aimed to explore the contact of distant cultures and students and their integration when working in a collaborative project within their respective business schools.

Learning competence on the use of communication channels can help students establish connections and strengthen their confidence in networking for professional purposes; very important considering previous studies demonstrating reluctance of students to establish new connections (Livingstone and Sefton-Green 2016: 249250). At the same time, this project was aimed at letting students increase their awareness of intercultural issues, whilst coordinating the task among group members in the best possible form (Sutanto et al. 2011). 
This study will use the term Global Virtual Team (GVT) as a more detailed description of the analysed task. Similar to Collaborative Online International Learning (COIL) initiatives, GVT belongs to the category of Virtual Exchange (VE), as described in O'Dowd (2018) and Ubachs and Henderikx (2018). In general, VE is "the engagement of groups of learners in extended periods of online intercultural interaction and collaboration with partners from other cultural contexts or geographical locations as an integrated part of their educational programmes and under the guidance of educators and/or expert facilitators" (O'Dowd 2018: 5). This definition expands on that of Taras et al. (2013), as it includes the figure of the educator in the ongoing learning process. As the article discusses, these activities require close monitoring from the teachers, as failing to do so can cause frustration among the students.

GVT activities can easily encompass the same challenges as a real face-to-face team would involve. "The most obvious benefit of GVT-based projects lies in the opportunity to experience the challenges of working in multicultural virtual teams and practice how to deal with them" (Taras et al. 2013:416) and exploring the learning cycle of experiencing, reflecting, thinking and acting (Kolb 1984). As such, these activities develop learning skills, as Ubachs and Henderikx (2018) noted.

For the students, they can enjoy the learning and experiential benefits of having an international experience without the travel costs. It becomes an affordable option to be involved in international projects and benefit from intercultural activities without having to spend money on travel expenses. However, it can still limit the satisfying personal experience of being immersed in another culture.

Institutions can use it to increase and enrich their academic offer and to ensure that all the students involved in GVT can enjoy an international experience. GVT are likewise a method of boosting the reputation of the institution through innovative programmes, with the subsequent improvement of student registration. Besides an enrichment of activities offered by the GVT, it stimulates a more international approach in the nature of the activity and the nationality of the participants. When GVT include several assignments adequately structured throughout several weeks, they can offer the chance to reflect on the learning process repeatedly (Taras et al. 2013).

A large part of the activities carried out in GVT-based projects lies in the development and reinforcement of transversal competencies, which, nowadays, have a very important role in university education. In fact, the focus on transversal competencies "emphasises the intentionality of teaching/learning and higher transferability in different fields and, therefore, the awareness of the possibility of conversion of acquired competencies into the capacity for action" (Zadra 2014:116). Competencies constitute an essential foundation in the professional world, and so they are gaining more emphasis in current educational models (De los Ríos et al. 2010: 1368). Today, enterprises demand competent professionals, and therefore, in universities such as ESIC Business \& Marketing School (Valencia campus, Spain) and SolBridge International School of Business (Daejeon, South Korea), it is stressed that one of the measures necessary for achieving employability is developing transversal skills and competencies (communication and languages, handling information properly, solv- 
ing problems, teamwork) to lead social processes, as stated in the Convención de Instituciones Europeas de Enseñanza Superior (Convención de Instituciones Europeas de Enseñanza Superior 2001).

Competencies can also be understood as an extension of the concept of ability and qualification and the competence of professional action as the sum of the competencies essential to carrying out a professional task well (De los Ríos et al. 2010: 1368). Indeed, a number of transversal competencies are expected to be achieved in addition to the specific competencies of each subject.

Given the digital nature of GVT, the study pays attention to the digital competence framework established by the EU. This consists of 21 digital competencies for citizens grouped in five different dimension areas (Vuorikari et al. 2016):

- Information and data literacy

- Communication and collaboration

- Digital content creation

- Safety problems

- Problem-solving

The case analysed in this paper integrated some of them throughout the several weeks it lasted, concluding in an overall satisfactory implementation and adoption by students and teachers alike. In this particular case, the study developed tasks aimed at information and data literacy, communication and collaboration among peers and internationally as well as solving the unexpected problems which could arise.

\section{Methodology}

\subsection{Data Collection}

The present study was carried out between two different Business Schools in distant countries: ESIC Business \& Marketing School (Valencia campus, Spain) and SolBridge International School of Business (Daejeon, South Korea). There was a total of 109 undergraduate students (69 in Spain and 48 in South Korea) of 23 different nationalities, distributed in 13 groups of 4-6 people in each institution. The project was divided in two parts, but it started with an ESIC-based activity that was not replicated at Solbridge.

First, ESIC students had to organise a student association developing an extraacademic activity that was missing in their home institution and which they considered sufficiently attractive for their classmates. Some examples at ESIC were organising an e-sport competition, a film club, a cooking club, a paddle tennis club, organising escape rooms nights, or organising events for exchange students, among others. In the case of Solbridge groups, they concentrated on exploring popular culture (karaoke, K-Pop, food culture) among the Spanish students. The assessment of 
the project would give additional marks if students were able to successfully organise the event and provide evidence to their classmates.

Second, and this corresponds to the GVT activity itself, students had to explore, with the help of the peer group in the other institution, the feasibility to organize that association in the partner institution. This activity was the only shared assignment in the course and represented $25 \%$ of the final mark in the case of ESIC and $15 \%$ in the case of Solbridge.

Several months prior to the beginning of the academic year, the lecturers of both institutions had already started exchanging emails, developing the project and making sure that the learning objectives and time organization of the semester would complement the course objectives. Hence both courses focused on the development of written and oral communication skills in a business environment, with tasks such as preparing reports and giving presentations.

Before the start of the activity, the students in both institutions were given a questionnaire asking them about the importance they gave to the learning outcomes developed in the course. The same questions were subsequently asked at the end of the activity to compare their views and observe the learning process, obtaining results on the importance students gave to the learning objectives before the activity and how important they were after the task, and assessing their learning in a similar way to Taras et al. (2013). The final questionnaire included questions that let them add qualitative information about their views of the activity.

As part of the research, students had to maintain several videoconferences with their peer groups to gather information, discuss their progress and support each other on the research on the partner city and institution. This proved to be one of the most challenging tasks, as the 7-hour time difference ( 8 hours at one point following Central European Time) between both countries represented a real challenge for most of the students, as they reflected on in their feedback. Some students mentioned that it was the first time they had used skype and manifested signs of anxiety before their first videoconference.

The coordination among the group members and the lecturers was originally devised as transversal, following recommended patters for similar GVT projects (Sutanto et al. 2011). There were two 'quality audits' in which lecturers asked about the documents each group was developing, together with the minutes for the videoconferences and meetings each group was holding. These activities were new for most of the participants, as they had no previous experience of taking minutes in meetings or even maintaining formal videoconferences.

At the end of the semester, students had to present a final report where they had to describe their fictive student association. They also had to give a presentation of their project in front of all the other students and analyse the relationship with their peers in the partner institution. In the case of the Spanish institution, the content of the presentations was going to be part of the final exam, as students would be asked about the relevance of the projects. On the presentation day, students would also decide what the best project was based on a questionnaire and assess the support and commitment of the members of their own group. The winning group would obtain one additional point voted by their own peers. 


\subsection{Data Collection}

In this study, a total of 109 students participated, of which 61 belonged to ESIC Business \& Marketing School (Valencia campus) and 48 to SolBridge International University.

The qualitative and quantitative information was carried out through a multiplechoice test, which the students completed twice. The first one at an early stage of the educational experiment and later after its completion, with the aim of comparing the results obtained.

The test evaluates the physical characteristics (origin, gender), the subjective importance that each student assigns to the activities carried out and the degree of satisfaction. Open opinion responses were used as well. 82 students from both institutions completed the survey, and no sampling was performed since all the data is included in the findings.

\section{Findings}

Among all the information collected in the questionnaires, one of the main estimators of satisfaction in the process is the students' response to the overall satisfaction with the methodology employed. The response admitted five levels of satisfaction, five corresponding to the highest satisfaction and one to the lowest. The same classification scheme was employed for the rest of the survey questions. As can be seen in Fig. 1, the final assessment of the project was highly satisfactory: $56 \%$ of the students found the activity to be highly satisfactory or satisfactory meanwhile only $11 \%$ found it not or not very satisfactory. When comparing the results obtained according to the institution, there is a significant difference between the responses of ESIC students and those of Solbridge: the latter valued the experience more positively, and with less variability than the students from ESIC (see Table 1). Taking into account only the students' answers about their overall satisfaction with the activity, it is difficult to deduce how the students determined their assessment.

From the different answers of the questionnaire and the open answers, it is possible to find some indicators of the strengths and weaknesses of this cultural exchange. Also, it should be taken into account that in the global assessment, not only the improvements in the communication and teamwork skills in the local group are evaluated, but part of that satisfaction is conditioned by the performance and communication skills of the other university group.

The lecturers themselves also expressed their overall satisfaction with the experience, despite the shared cultural barriers: "Actually, I really enjoyed the experience. All of the feedback that I received indicated that the students enjoyed the collaboration as well. One of the major problems that the students experienced was the major time differences and language barriers. I explained that major time differences could be expected in almost all globalized economic partnerships and collaborations 


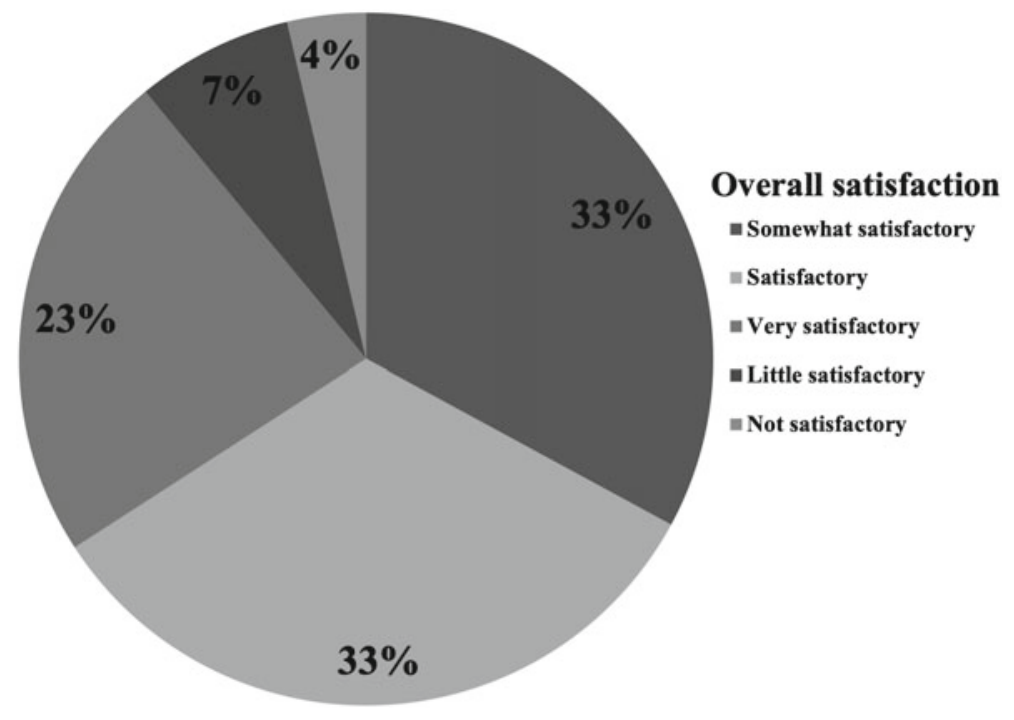

Fig. 1 Overall satisfaction of the virtual exchange between Spain and South Korea

as well as language problems. So, essentially, I explained to the students that they may experience similar problems in real-life situations. Overall, it was an excellent experience for myself and my students" (Quinn, SolBridge lecturer, personal communication).

The students of both institutions were asked about the importance in the learning process of the different activities carried out. The items evaluated were: writing e-mails in an adequate style, taking minutes in a meeting (taking min), writing reports and proposals leading to making decisions, being aware of cultural differences, clearly illustrating in writing and orally the most relevant issues in a situation (illustrating), debating on current events with increase ease (debating), explaining and describing the socio-political situation of a country (explaining), identifying the different points in favour and against in any given situation in order to adopt a position (identifying), analysing situations in order to negotiate successfully (analysing), speaking in public in English fluently (speaking).

From the answers obtained in the previous items, some will be studied in more detail. The results for writing e-mails in an adequate style (Fig. 2) showed that $83 \%$ of the students considered it to be important or very important to write e-mails in a proper style; meanwhile, only $17 \%$ thought that was not important. Exchanging e-mails was not, however, as important to collaboration of the students as expected, given that many of the students resorted to other means of communication, including their favourite social networks, once the contact had been established. Those who maintained e-mails as a form of communication kept a casual style throughout the project. As in the previous case, there existed a significant difference between the answers when the factor institution was considered. SolBridge considered this activ- 
Table 1 ANOVA for the different items evaluated depending on the institution

\begin{tabular}{l|l|l|l|l|l|l}
\hline \multirow{2}{*}{$\begin{array}{l}\text { Dependent } \\
\text { variable }\end{array}$} & \multicolumn{2}{|l|}{ Average } & \multicolumn{2}{l|}{ Std. deviation } & P-value & Difference \\
\cline { 2 - 6 } & ESIC & SolBridge & ESIC & SolBridge & & \\
\hline $\begin{array}{l}\text { Overall } \\
\text { satisfaction }\end{array}$ & 3.26 & 4.35 & 1.01 & 0.67 & 0.0000 & Significant \\
\hline $\begin{array}{l}\text { Writing } \\
\text { e-mails }\end{array}$ & 2.87 & 3.32 & 0.83 & 0.79 & 0.0131 & Significant \\
\hline $\begin{array}{l}\text { Taking the } \\
\text { minute }\end{array}$ & 2.64 & 3.27 & 0.74 & 0.65 & 0.0002 & Significant \\
\hline $\begin{array}{l}\text { Writing } \\
\text { reports }\end{array}$ & 3.12 & 3.41 & 0.76 & 0.68 & 0.0825 & $\begin{array}{l}\text { Non- } \\
\text { significant }\end{array}$ \\
\hline $\begin{array}{l}\text { Cultural } \\
\text { differences }\end{array}$ & 3.34 & 3.72 & 0.78 & 0.45 & 0.0175 & Significant \\
\hline $\begin{array}{l}\text { Illustrating } \\
\text { in writing }\end{array}$ & 3.32 & 3.27 & 0.70 & 0.59 & 0.7707 & $\begin{array}{l}\text { Non- } \\
\text { significant }\end{array}$ \\
\hline $\begin{array}{l}\text { Debating on } \\
\text { events }\end{array}$ & 3.04 & 3.21 & 0.59 & 0.56 & 0.2084 & $\begin{array}{l}\text { Non- } \\
\text { significant }\end{array}$ \\
\hline $\begin{array}{l}\text { Explain and } \\
\text { describe }\end{array}$ & 2.55 & 3.17 & 0.89 & 0.66 & 0.0014 & Significant \\
\hline $\begin{array}{l}\text { Identifying } \\
\text { points }\end{array}$ & 3.28 & 3.38 & 0.77 & 0.682 & 0.5738 & $\begin{array}{l}\text { Non- } \\
\text { significant }\end{array}$ \\
\hline $\begin{array}{l}\text { Analysing } \\
\text { situations }\end{array}$ & 3.28 & 3.45 & 0.69 & 0.63 & 0.2889 & $\begin{array}{l}\text { Non- } \\
\text { significant }\end{array}$ \\
\hline $\begin{array}{l}\text { Speaking in } \\
\text { public }\end{array}$ & 3.73 & 3.38 & 0.52 & 0.78 & 0.0155 & Significant \\
\hline
\end{tabular}

ity more important than ESIC students (Table 1), and this higher result can also be due to cultural differences. Whereas at ESIC, the lecturer stressed the importance of emailing students from the other institution in a proper manner, many of the students resorted to one or two emails and continued conversation through various social networks. This trend in the use of social networks has been manifested repeatedly in recent years during activities carried out in class. It should be noted that the lecturers did not disagree on the use of different communication channels, including the most innovative and globalized social networks. In this context, however, the item that was intended to be evaluated is the formalization of a text (in the form of an e-mail) following some standards of correction and formality.

Cultural differences are an expected issue that adds complexity to the activity, and overcoming these strengthens intercultural communication skills. Indeed, 91\% of the students considered cultural differences as important or very important (Fig. 3). Both participating groups consisted of students of different nationalities and distant cultures. It is interesting to measure the appreciation that students themselves had about cultural differences during the activity and to study the different weights in the answers, according to the origin group. There was a slight difference between 


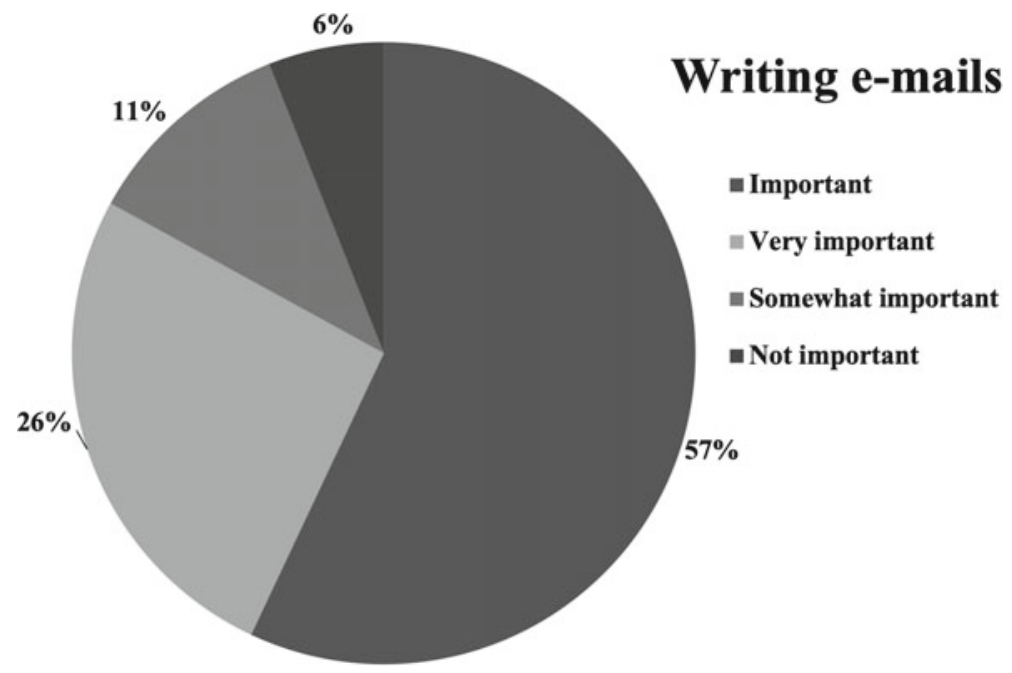

Fig. 2 Students' opinion on the item writing e-mails in an adequate style

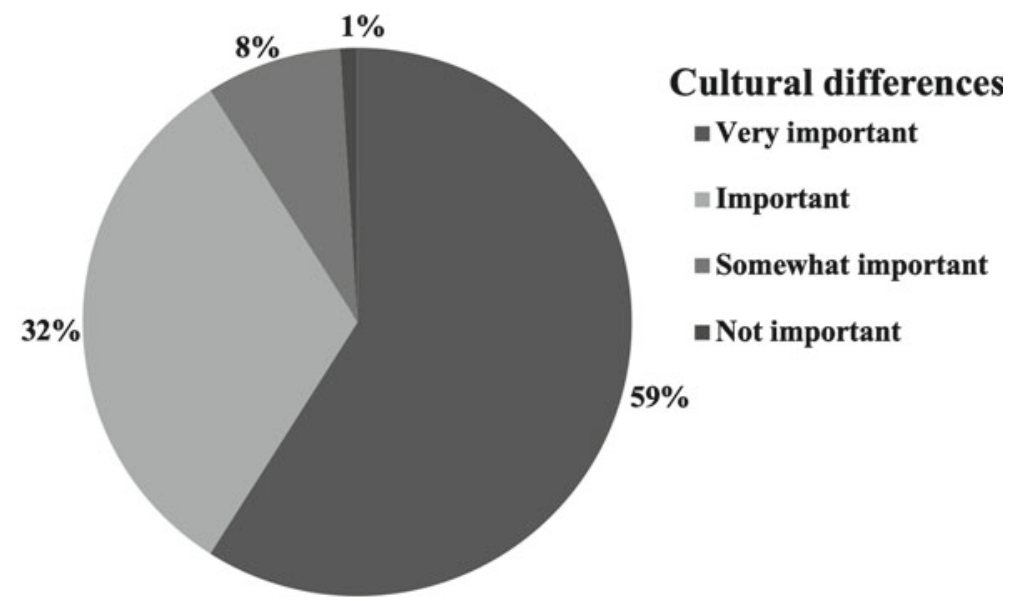

Fig. 3 Students' opinion on the item being aware of cultural differences

the means obtained (3.34 ESIC vs. 3.72 SolBridge). To verify whether the difference between the means is significant or not, an ANOVA test was performed, obtaining a significant difference $(p$-value $=0.0175)$ between the averages and standard deviations of the answers of both groups.

The awareness of cultural differences among ESIC students may stem from the lack of access to cultural references of the two major nationalities of SolBridge students (South Korea and China). This opens new possibilities for further research 


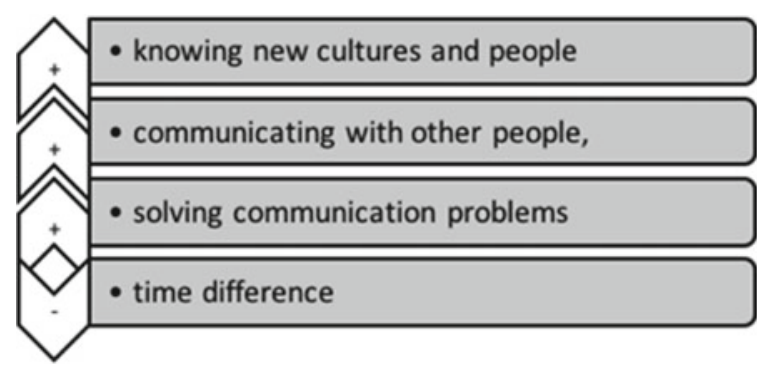

Fig. 4 Students' opinion on the best part of the virtual exchange activity

and is particularly welcome, as most ESIC students were majoring in International Business.

When asked about the other items in the survey, students from both institutions also showed significant differences in taking minutes, explaining and describing, and speaking in public. However, non-significant differences between students of both institutions were found in the items writing reports, illustrating in writing, debating on events, identifying points and analysing situations (Table 1).

The results on the best part of the virtual exchange activity show that getting to know new cultures and people, communicating with other people, and solving communication problems have been pointed out by $90 \%$ of the students as the most important outcomes. On the contrary, the part of the activity that caused most problems to the students was indisputably the time difference ( 8 hours), forcing them to adapt to each other to avoid obstructing communication (Fig. 4).

In order to numerically evaluate these findings, the study divided the responses into four main categories: (improvement in) teamwork, (improvement in learning how to deal with) cultural differences, (improving) communication skills, (improvement in learning strategies of) problem-solving (Fig. 5).

From the answers obtained, $31 \%$ of students perceived an improvement in their teamworking skills, $46 \%$ perceived an improvement in their communication skills, $18 \%$ learnt strategies to better deal with cultural differences in communications, and $7 \%$ claimed to have improved problem-solving skills.

The item "What have you learned from working and communicating?" in the survey was intended to obtain information on the skills that the students have improved during this cultural exchange. Figure 6 shows a word cloud, in which the size of the words is proportional to the number of times these words are mentioned in the answers. It clearly emphasizes the communication, teamwork and public speaking skills. 


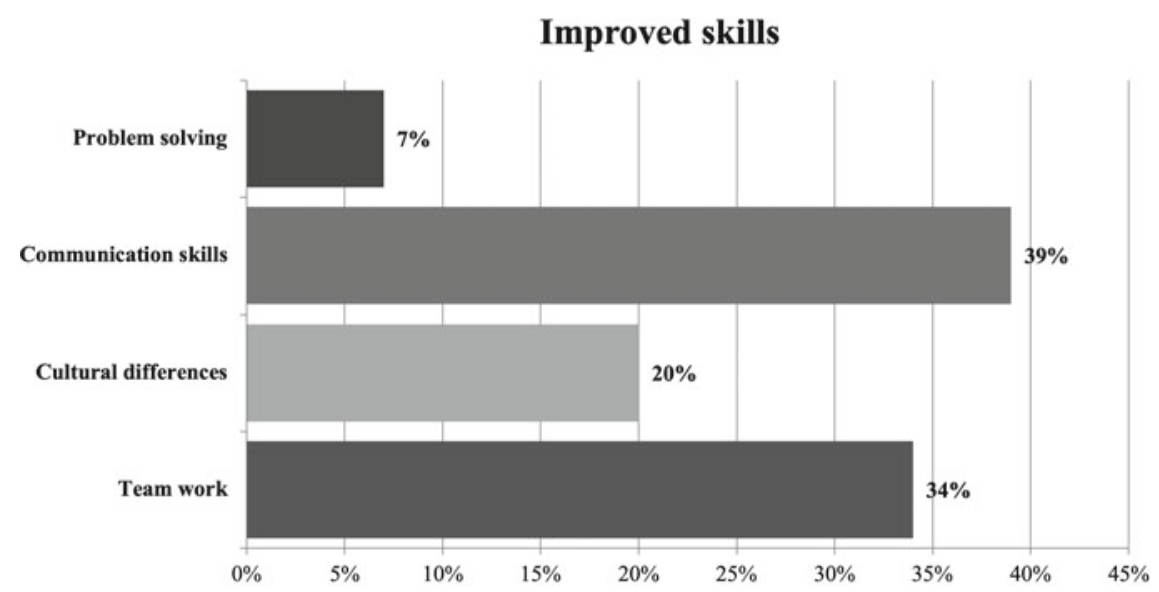

Fig. 5 Students' opinion on the best part of the virtual exchange activity

Fig. 6 Word Cloud on the enhanced skills after the virtual exchange activity

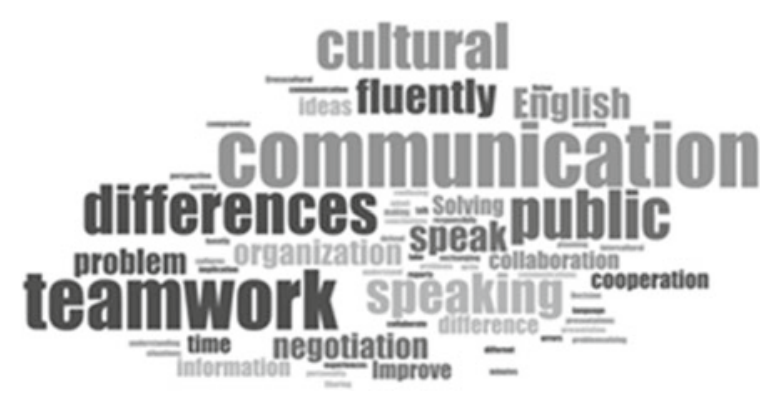

\section{Conclusions}

This case study has contributed to a broader understanding of virtual exchange activities in higher education in different cultural contexts in terms of the types of activities engaged, the perceived value and learning outcomes as well as shared challenges. This understanding will help to define common strategies in the practice of virtual exchange and to achieve greater integration within university curricula, given their demonstrated improvement of the skills of the participants (Taras et al. 2013).

Virtual exchange activities contribute not only to the improvement of students' language and digital skills but to other transversal competencies such as, data literacy, problem-solving and teamwork, which have become more important in an increasingly complex and competitive world of global connections. Students described how effective the project had been in improving their teamwork and communication skills. However, subsequent projects could evaluate the real improvements for a better understanding and comparison of the results. Designed in a more participative way, these activities could open up a space for various forms of intercultural learning. Through this collaborative communication space, students could not only improve a 
wide range of digital competencies needed in a professional level, but also to be part of international learning networks, which can become formal or informal networks that form and inform their future career pathway.

\subsection{Limitations and Implications for Future Research}

One major hurdle in the activity is that the students were aware that they were working on a fictional objective. Had they been working in a real-life task in which they had to establish a student association in their own institutions, their enthusiasm for the project would probably have been higher. This could trigger an additional motivating factor when establishing subsequent similar projects, where students collaborate in a real activity which they build from scratch, and in which they understand the requirements of its real implementation. Additionally, some students misinterpreted the elaboration and expectation of the activity, despite the effort made by the instructors to establish the objectives and activities. Of course, misinterpretation of the shared project could still take place in a real environment. Nevertheless, some conclusions for the future can be drawn.

Students may have benefitted from more pedagogical support, greater clarity in the tasks to be performed and in the objectives of the activity. Problems may also result from a lack of motivation and confidence in the project they were working on. As a matter of fact, some ESIC students expressed a growing lack of confidence in the feasibility and implementation of the project in their own university throughout the semester. When they were first asked about how confident they were about their project being implemented in the university, they expressed an overwhelming confidence, but, as days passed, and they realised how time-consuming the organisation of activities were and the little impact some decisions had on their peers, there was an increasingly dismal view. Hence it is of paramount importance to offer adequate monitoring and support of students and their activities to ensure their enthusiasm and learning attitude does not disappear. Likewise, teachers in both institutions agreed on the necessity to describe even more carefully the tasks and set clear objectives for future projects. In addition to the perception of improvement in some skills, such as teamworking, expressed by the students in the survey, subsequent projects could assess how the improvement takes place and how they apply newly acquired abilities in the performed activities.

Acknowledgements The authors would like to express their gratitude to the reviewers of previous versions of this article, and particularly Dominic Orr, for their suggestions. They would especially like to thank James E. Quinn, Director of English Development at Solbridge International School of Business, for his collaboration in this cross-institutional collaborative team. Without his mutual interest, this activity could not have taken place. Finally, the authors would like to thank every student involved in the project and all their positive contributions. 


\section{References}

Bozda $\breve{g}$, Ç. (2018). Intercultural learning in schools through telecollaboration? A critical case study of eTwinning between Turkey and Germany. The International Communication Gazette, 80(7), 677-694. https://doi.org/10.1177/1748048518802221.

Convención de Instituciones Europeas de Enseñanza Superior. (2001). Perfilando el Espacio Europeo de la Enseñanza Superior. Available online at: http://www.eees.es/pdf/Salamanca2001. pdf (accessed 6 December 2019).

De los Ríos, I., Cazorla, A., Díaz-Puente, J.M., \& Yagüe, J.L. (2010). Project-based learning in engineering higher education: two decades of teaching competences in real environments. Procedia Social and Behavioral Sciences, 2, 1368-1378. https://doi.org/10.1016/j.sbspro.2010. 03.202.

Jurše, M. \& Matjaž, M. (2011). The complexities of business school alignment with the emerging globalisation of business education. Kybernetes, 4(9/10), 1440-1458. DOI:https://doi.org/10. $1108 / 03684921111169477$.

Kupriyanova, V., Esterman, T. \& Sabic, N. (2018) Efficiency of Universities: Drivers, Enablers and Limitations. In A. Curaj, L. Deca \& R. Pricopie (Eds.), European Higher Education Area: The Impact of Past and Future Policies (pp. 603-618). Cham: Springer Open. https://doi.org/10. 1007/978-3-319-77407-7_36.

Kolb, D. A. (1984). Experiential learning. Englewood Cliffs, NJ: Prentice Hall.

Livingstone, S. \& Sefton-Green, J. (2016). The class: Living and Learning in the digital age. New York: NYU Press.

O'Dowd, R. (2018). From telecollaboration to virtual exchange: state-of-the-art and the role of UNICollaboration in moving forward. Journal of Virtual Exchange, 1, 1-23. Research-publishing.net https://doi.org/10.14705/rpnet.2018.jve.1.

Rehg, M., Gundlach, M. \& Grigorian, R. (2012). Examining the influence of cross-cultural training on cultural intelligence and specific self-efficacy. Cross-cultural management, 19(2), 215-232. https://doi.org/10.1108/13527601211219892.

Sutanto, J., Kankanhalli, A. \& Tan, B. C. Y. (2011). Deriving IT-mediated tasks coordination portfolios for Global Virtual Teams. IEEE Transactions on Professional Communication, 54(2), 133-151. https://doi.org/10.1109/TPC.2011.2121630.

Taras, V., Caprar, D. V., Rottig, D., Sarala, R. M., Zakaria, N., Zhao, F., Jiménez, A., Wankel, C., Weng, S. L., Minor, M., Bryła, P., Ordeñana, X., Bode, A., Schuster, A. M., Vaiginiene, E., Froese, F. B., Bathula, H., Yajnik, N., Baldegger, R., \& Huang, V. Z. Y. (2013). A global classroom? Evaluating the effectiveness of global virtual collaboration as a teaching tool in management education. Academy of Management Learning and Education, 12(3), 414-435. https://doi.org/ 10.5465/amle.2012.0195.

Ubachs, G. \& Henderikx, P. (2018). EADTU Mobility Matrix. Maastricht: (EADTU) European Association of Distance Teaching Universities. Retrieved from: https://bit.ly/2TgbT89.

Vuorikari, R., Punie, Y., Carretero, S. \& Van den Brande, L. (2016). DigComp 2.0: The Digital Competence Framework for Citizens. Update Phase 1: The Conceptual Reference Model. Luxembourg Publication Office of the European Union. https://doi.org/10.2791/11517.

Zadra, C. (2014). Schooling and lifelong learning. The role of transversal key Competences. Procedia - Social and Behavioral Sciences, 116, 4727-4731. https://doi.org/10.1016/j.sbspro.2014. 01.1016. 
Open Access This chapter is licensed under the terms of the Creative Commons Attribution 4.0 International License (http://creativecommons.org/licenses/by/4.0/), which permits use, sharing, adaptation, distribution and reproduction in any medium or format, as long as you give appropriate credit to the original author(s) and the source, provide a link to the Creative Commons license and indicate if changes were made.

The images or other third party material in this chapter are included in the chapter's Creative Commons license, unless indicated otherwise in a credit line to the material. If material is not included in the chapter's Creative Commons license and your intended use is not permitted by statutory regulation or exceeds the permitted use, you will need to obtain permission directly from the copyright holder. 